\title{
ACERCA DA CONSTRUÇÃO DE UMA LEGISLAÇÃO DE DIREITOS HUMANOS DE CARÁTER UNIVERSAL
}

\author{
ABOUT THE CONSTRUCTION OF A UNIVERSAL \\ LEGISLATION OF HUMAN RIGHTS
}

Marcelo Pereira de Mello ${ }^{1}$

\begin{abstract}
RESUMO: Este artigo descreve duas posições ideológicas fundamentais na defesa da normatização e aplicação da legislação sobre os direitos humanos: universalistas e relativistas. A partir dessa descrição sustenta a defesa da posição dos universalistas tendo por fundamento uma revisão do conceito de cultura que, ao contrário dos relativistas e dos multiculturalistas, é entendida como fundamentalmente comunicativa e niveladora de diferenças. Parte, ainda, da perspectiva de que as culturas são complexos simbólicos que constituem um acervo com o qual os nativos de uma sociedade interpretam o mundo físico, dão sentido às relações sociais das quais participam e com o qual criam as condições subjetivas de interação com outras sociedades. A interpretação e a comunicação, portanto, são dois aspectos inerentes dos sistemas culturais e fundamentais das relações interculturais. A partir dessa noção de cultura sustenta que a cultura legal de cada sociedade, i. e., as noções do que é lícito e ilícito, encerram condições de intercomunicação que tornam possíveis diálogos e troca de experiências sobre as noções de justo e injusto, que podem servir de base a construção de uma legislação universal de direitos humanos.
\end{abstract}

Palavras Chave: Direito Humanos; Cultura; Cultura Legal; Transplante Legal; Transculturalismo; Universalismo.

\begin{abstract}
This article describes two fundamental ideological theories in the defense of ruling and application of human rights legislation: the universalism and relativism. Parting from this description, it is possible to defend the universalism doctrine as its fundament is a review of the concept of culture that, different from the relativists and multiculturalists, is understood as communicative and balanced of the differences. It should be mentioned, that this article adopts the thesis that cultures are symbolic complexes which constitute an archive in which natives of a society interpret the physical world, create reason to social relations that they are part of, and create subjective conditions of interaction with other societies. The interpretation and communication, therefore, are two elements inherent of cultural systems and they are essential to intercultural relations. According to this point of view, the legal culture of every society, i.e. the notions of the meanings of what is illegal or legal cease conditions of intercommunication which make possible dialogs and exchange of experiences about the notions of what is fair and unfair, which can give support to the building of an universal legislation of human rights.
\end{abstract}

Keywords: Human rights; Culture; Law culture; Law transplant; Transculturalism; Universalism.

\footnotetext{
${ }^{1}$ Professor Associado II da Universidade Federal Fluminense, Departamento de Sociologia, subcoordenador do Programa de Pós - Graduação em Sociologia e Direito PPGSD-UFF
} 


\section{INTRODUÇÃO}

Há uma clivagem fundamental que opõe nos dias atuais os defensores da fundamentação dos Direitos Humanos entre universalistas e relativistas. Os primeiros, os universalistas, acreditam que a normatização e a aplicação dos Direitos Humanos devam ocorrer de forma igualitária em qualquer Estado-Nação. Acreditam que os direitos fundamentais das pessoas têm, no limite, as mesmas potencialidades e restrições, e que o indivíduo universalmente considerado como sujeito das ações políticas deva ser o repositório dos direitos, dos deveres e das garantias de um sistema jurídico planetário de proteção. Os relativistas, por seu turno, defendem que a constituição e a aplicação dos Direitos Humanos devam se adaptar aos diversos modos de vida existentes em cada parte do planeta com a conseqüente acomodação dos pontos de vistas contrários e culturalmente sustentáveis. Daí serem chamados, também, de multiculturalistas. Relativistas de uma maneira geral acreditam que particularidades regionais, em razão da cultura nacional e da soberania nacional, devam ser consideradas na definição do acervo dos Direitos Humanos. Multiculturalistas são ainda mais restritivos neste aspecto, defendendo que mesmo no interior de um mesmo país, região ou cultura local existem subculturas e particularidades que devem ser respeitadas.

Até aqui relativistas e multiculturalistas têm prevalecido no debate e o processo de institucionalização dos Direitos Humanos têm se desdobrado em diversos sistemas de proteção: o Europeu, o Americano e o Asiático, este em fase de implementação.

Neste debate, nos situamos entre os universalistas e ao longo deste artigo procuramos fundamentar a nossa posição de que direitos e garantias devem ser fixados a partir do reconhecimento de que é o indivíduo, na condição de real portador de direitos e deveres, e como protagonista dos sistemas jurídicos, que deve ser protegido. Inclusive de sua "cultura" e "tradição" quando estas o ameaçarem na proteção da sua vida e no seu livre arbítrio para expressar posições, opiniões e na realização de ações que não restrinjam ou impeçam os direitos de outrem. Inúmeros exemplos históricos ilustram sobejamente o quanto as posições de grupo e coletivistas podem carregar expedientes autoritários e expressar posições totalitárias frontalmente agressivas à integridade da liberdade política, da saúde, e às manifestações vitais das pessoas.

Para refletirmos sobre essas questões e no sentido de re-qualificarmos o conceito de cultura do relativismo e do multiculturalismo que fundamentam as posições dos relativistas nas questões dos Direitos Humanos, nosso objetivo será discutir sobre os processos universais de constituição do Direito nas sociedades contemporâneas. De tal maneira que esses debates in- 
corporem as informações sociológicas e antropológicas sobre a cultura e superem os paradoxos paralisantes entre o global e o local, entre o universal e o tradicional. Temos plena consciência de que a tarefa não é trivial.

Com estes propósitos iremos desenvolver o conceito de Transculturalismo Legal. Nossa tese central é a de que a cultura fornece elementos de comunicação entre sociedades as mais diversas e que uma redefinição sociológica do conceito de cultura permite-nos vislumbrar as possibilidades de entendimento transcultural das normas que visam a garantir os direitos fundamentais num plano universal.

\section{CULTURA E TRANSCULTURALISMO}

Sem negar obviamente as conquistas sociais e políticas propiciadas pelo relativismo, pelo multiculturalismo e pelo pós-modernismo acerca do reconhecimento e legitimidade das diferenças culturais, nosso ponto de partida tangencia estas questões para nos fixarmos em algo diverso: a comunicação entre as culturas; e parte de uma indagação: É possível pensarmos a lei e mais amplamente o Direito como meios de comunicação entre povos com diferentes tradições e culturas? sto implica, evidentemente, na reflexão sobre o que é cultura e sobre a possibilidade de identificarmos princípios transculturais, ou seja, elementos transversais às diferentes culturas que servem de veículos para pensarmos alguns princípios de diferença, mas, principalmente, de semelhanças entre valores e tradições que sejam constituintes de princípios universais do Direito, tais como os chamados Direitos Humanos. O transculturalismo não nega, portanto, as diferenças culturais, mas problematiza o engessamento do conceito de culturas como totalidades idiossincráticas impermeáveis às mudanças próprias da relação umas com as outras.

O conceito de cultura que trabalhamos nesta perspectiva é próximo ao alcançado por Geertz (2001) a partir de Max Weber e que enfatiza os aspectos subjetivos e interpretativos da produção de sentidos pelos indivíduos em interação. Como afirma este autor: "Como sistemas entrelaçados de signos interpretáveis..., a cultura não é um poder, algo ao qual podem ser atribuídos casualmente os acontecimentos sociais, os comportamentos, as instituições ou os processos; ela é um contexto, algo dentro do qual eles podem ser descritos de forma inteligível - isto é, descritos com densidade" (GEERTZ, 2001, p. 32).

Ao que acrescenta: "Procurar o comum em locais onde existem formas não usuais ressalta não, como se alega tantas vezes a arbitrariedade do comportamento humano, mas o grau no qual o seu significado varia de acordo com o padrão de vida através do qual ele é informado. 
Compreender a cultura de um povo expõe a sua normalidade sem reduzir sua particularidade" (GEERTZ, 2001, p. 32).

Acreditamos que esta concepção de cultura tem a vantagem de se destacar das abordagens classificatórias dos evolucionistas e a sua ênfase na produção de artefatos que distinguem as sociedades em mais ou menos desenvolvidas; bem como se apresenta mais específica que a idéia de cultura dos relativistas que a representa como um todo de conhecimentos, "um acervo comum" idiossincrático com os quais os indivíduos se comunicam no interior de uma sociedade.

Este tipo de perspectiva da cultura abre-nos uma visão diferente para entendermos, por exemplo, um problema básico da teoria sociológica a respeito da maneira como as condições materiais e naturais do ambiente relativas às necessidades de produção e reprodução social encontram sua correspondência cultural. Também, permite-nos ponderar sobre a forma como sociedades com diferentes "modos de produção" e "estádios de desenvolvimento" se relacionam umas com as outras.

Reinterpretando a clássica formulação marxista sobre esta questão, ou seja, da produção como apropriação da natureza segundo os padrões fixados pelas diferentes sociedades, Marshall Sahlins (2007) afirma que a expressão de Marx segundo a qual a cada sociedade corresponde um "modo de produção determinado", significa que um sistema de produção é a forma relativa de uma necessidade absoluta, um modo histórico peculiar de responder às exigências humanas. E prossegue: “Construídos em relação às forças da natureza-e, em geral, também em relação às pressões provenientes de outras sociedades-, todos os esquemas culturais conhecidos pela história foram produto, justamente, dessa circunstância pragmática" (SAHLINS, 2007, p. 445).

Segundo Sahlins, tal proposição implica na compreensão de que o curso histórico do desenvolvimento das sociedades deve ser encarado como um "processo cultural". Não se trata, então, de desconhecer o poder invasivo do capitalismo ocidental, sua força coercitiva e potencialmente destrutiva de outros "modos de produção", mas de reconhecer que essas forças devastadoras modernas passam por um processo de re-significação na ordem local das coisas. Segundo Sahlins (2007, p. 445).: “[...] as mudanças históricas na sociedade local também estão em continuidade com o esquema cultural suplantado, enquanto a nova situação vai adquirindo uma coerência cultural de natureza distinta".

Isso significa, segundo nosso entendimento, que os esforços de compreensão das sociedades "tradicionais" e "aborígines" não pode ser reduzida a uma perspectiva que limita os 
contatos interculturais a uma denúncia de invasão material apenas, e que resulta na proposição teleológica da submissão da mais "simples" a mais "complexa". Na verdade, essa suposição expõe a caráter preconceituoso destas análises na medida em que não reconhecem a capacidade dos sistemas culturais de imporem seu "sistema mundo" à influência externa. Não basta, portanto, prossegue o autor, afirmar que a economia global expõe a economia local a uma corrupção cultural, mas compreender a forma como as mercadorias ocidentais são apropriadas pelos diferentes sistemas culturais.

Sahlins conclui: "Portanto, o sistema mundial não é uma física de relações proporcionais entre 'impactos' econômicos e 'reações' culturais. Os efeitos específicos das forças material-globais dependem das várias maneiras pelas quais elas são mediadas nos esquemas culturais locais". (SAHLINS, 2007, p. 446).

O conjunto destas observações acerca de uma teoria da cultura mais interpretativa e menos teleológica das interações interculturais nos mostram o quanto as perspectivas relativista e multiculturalista podem abrigar ainda que involuntariamente preconceitos com respeito à uma suposta incapacidade das culturas locais reagirem ativamente aos contatos com culturas diferentes, ainda que supostamente portadoras de condições econômicas superiores e com forte poder de persuasão e coerção.

Nossa concepção de cultura procura, assim, aproveitar as diferentes observações de Geertz e Salhins. Nosso entendimento particular é o de que as culturas são complexos simbólicos que constituem um acervo com o qual os nativos de uma sociedade interpretam o mundo físico, dão sentido às relações sociais das quais participam e com o qual criam as condições subjetivas de interação com outras sociedades. A interpretação e a comunicação, portanto, são dois aspectos inerentes dos sistemas culturais e fundamentais das relações interculturais. A cultura é o meio essencial de responder aos desafios da reprodução social por intermédio de um aporte de conceitos e significados que ordenam o mundo todo das coisas e das pessoas que compõem o universo mais próximo e imediato dos indivíduos bem como os mundos mais distantes: reais, intuídos ou imaginados. Não há, portanto, em nosso juízo, qualquer possibilidade de que as culturas sejam subservientes umas às outras devido a qualquer suposto de superioridade material ou capacidade interpretativa. Força interpretativa e subjetividade que estão na base da dinâmica e da mudança social não são hierarquizáveis. 


\section{“CULTURA LEGAL": REINTERPRETANDO O CONCEITO}

Dentro do conjunto de sentidos, valores, moralidades e instituições que compõem o universo cultural de qualquer sociedade trabalharemos com uma subcultura especial e que a guisa de aproveitamento dos estudos já existentes sobre o tema chamaremos aqui de "cultura legal" ou "cultura jurídica". Cultura legal para nossos fins representa o conjunto de valores, crenças, acervo de fórmulas cognitivas e métodos de interpretação e comunicação de sentidos compartilhados por uma comunidade no que respeita as suas concepções sobre a lei e sobre as definições formalizadas em linguagem sobre o lícito e o ilícito e sobre as instituições que garantem as noções compartilhadas sobre o justo (o Estado, a Justiça, a polícia, rituais de expiação, etc.).

As análises mais tradicionais de cientistas sociais sobre o sistema legal partem quase sempre da mesma hipótese geral: mudanças na sociedade, no equilíbrio de forças entre os diversos grupos sociais implicam, inexoravelmente, em mudanças da lei. Essa perspectiva implica, então, na idéia amplamente difundida na sociologia jurídica de que a lei é um fenômeno determinado pelas condições sociais mais abrangentes de determinada sociedade, sejam elas de natureza religiosa, moral ou cultural. A perspectiva marxista desta abordagem, sócio-centrada, acrescenta a esta fórmula a determinação dos interesses econômicos dos grupos privilegiados como leitmotif das transformações na lei.

As respostas mais comuns sobre como essas transformações ocorrem, a partir desta perspectiva sócio-centrada, tendem a estabelecer uma relação direta e determinante entre algum evento ou seqüência de eventos nas diversas esferas da vida coletiva e as mudanças dos sistemas legais: -por exemplo, a ascensão política da burguesia e a conseqüente separação constitucional dos poderes, ou algo menos grandioso e dramático como o surgimento da informática e as subseqüentes alterações no sistema legal do tipo direitos autorais na rede, redefinições do direito de privacidade das informações pessoais, segurança e demais problemas associados.

Lawrence Friedman (1975) acha que este entendimento do processo de interação entre mudanças na sociedade e impactos no sistema legal está assentado em teses muito genéricas e sem especificidade, e propõe para esta análise um passo intermediário no interior desse processo geral. Da seguinte forma: mudanças nos padrões das relações sociais oriundas de qualquer natureza (econômica, política ou moral) conduzem a transformações nos valores e nas atitudes dos agentes sociais com respeito à lei, na "cultura legal", que por seu turno conduzem às mudanças no sistema legal. O conceito de "cultura legal” de Lawrence Friedman (1975) procura, 
assim, qualificar a assunção genérica da Sociologia acerca da existência de determinações recíprocas entre as relações sociais e o Direito descrevendo um dispositivo sócio-cultural de interação das relações sociais no Direito: a "cultura legal” descreve esta etapa específica do processo de configuração institucional do sistema jurídico resultante da fricção entre as relações sociais cotidianas e as leis que são criadas em seu contexto. Sua tese central a este respeito pode ser sintetizada na seguinte equação: relações sociais $\rightarrow$ culturas legais [jurídica] $\rightarrow$ direito

A suposição de que discordamos da teoria de Lawrence Friedman é a da existência de uma articulação funcional e não-problemática entre as diferentes culturas legais e o sistema social.

Nossa posição a este respeito é a de que as subculturas que compõem os sistemas legais, pela razão de que são traspassadas pelas experiências específicas dos grupos considerados e, também, devido à apropriação desigual dos recursos materiais e simbólicos postos à disposição destes agentes, jamais chegam a compor verdadeiramente um sistema legal estruturado ou um padrão unívoco de funcionamento do sistema legal integrado por "culturas legais". Acreditamos, pelo contrário, que a ação prática dos agentes deriva mais dos seus esforços cognitivos e interpretativos do sistema legal formalizado em normas e leis que, na realidade, nem sempre se integram e estão, ao contrário, sujeitas a permanente conflito e contradição frente às interpretações possíveis.

Nossa apropriação crítica do conceito de "cultura legal" se dá exatamente pela percepção de que a efetividade da lei e o funcionamento das instituições legais são resultados de consensos cognitivos e acordos interpretativos precários que fazem do Direito e da jurisprudência produções constantemente revisadas em função de problemas práticos relacionados à inconsistência dos padrões éticos e morais dominantes em determinados ambientes e contextos. Instituições jurídicas não são entidades fossilizadas pela sedimentação progressiva de avanços da legislação e do saber jurídico, mas são, na nossa perspectiva, referências para a ação, "molduras" institucionais que fornecem parâmetros gerais e referenciais para a atuação interpretativa dos agentes sociais.

Nossa apropriação do conceito de "cultura legal" introduz, ainda, a mediação dos conceitos de "legitimidade" e "dominação" para entendermos como se constituem e se afirmam, no interior de uma sociedade, as diferentes culturas legais. Pensamos que as interações sociais e o complexo simbólico que orienta as expectativas recíprocas dos agentes em interação conformam ações referenciadas nas diferentes representações da lei, feitas de acordo com os recursos cognitivos e de poder material e simbólico que cada indivíduo ou grupo mobiliza, constituindo culturas legais eventualmente concorrentes. Este campo tensionado entre a adequação de ações 
e expectativas consolidadas em culturas legais, somadas a uma multiplicidade de recursos de poder, materiais e cognitivos, que são mobilizados pelos agentes, seleciona desigualmente valores, procedimentos e leis conferindo-lhes um poder desigual nas disputas pela legitimidade entre os diferentes padrões de culturas legais presentes numa sociedade. Podemos sintetizar nossa concepção igualmente numa equação: relações sociais $\rightarrow$ interpretação $\rightarrow$ comunicação $\rightarrow$ culturas legais [jurídicas] $\rightarrow$ dominação $\rightarrow$ legitimidade $\rightarrow$ Direito.

Feitas todas essas ressalvas, estamos prontos a entender porque o conceito de cultura legal que defendemos pode e deve ser aplicado à compreensão das distintas sociedades humanas independentemente do estágio de desenvolvimento econômico ou da organização e formalização dos sistemas legais das diferentes sociedades. Nossa tendência é admitirmos com facilidade a expressão cultura legal quando referenciada nos sistemas legais do capitalismo ocidental e sua organização típica das leis em códigos especiais e sua institucionalidade consolidada em tribunais, cortes, instancias recursais hierarquizadas, profissionais especializados, todos legitimados e abrigados numa organização estatal centralizada; mas, talvez, possamos opor restrições a operar com o mesmo conceito de cultura legal nas sociedades "diferentes" das nossas pela comparação por estes critérios.

Ora, da mesma forma que uma sociedade indígena não deixa de ter política por causa da inexistência de uma organização estatal, conforme o estudo sobre a política nas sociedades sem Estado de Pierre Clastres (1988), também a inexistência de códigos legais escritos não tornam as sociedades indígenas, por exemplo, desprovidas de lei e mesmo de uma intensa atividade legislativa.

\section{TRANSPLANTES LEGAIS}

Há um reconhecimento relativamente consensual a respeito de que os sistemas jurídicos são dinâmicos e que as leis mudam no tempo com relativa rapidez. A forma como ocorrem essas mudanças e as causas das transformações dos sistemas jurídicos e culturas legais não são, entretanto, unívocas entre os que reconhecem esse dinamismo próprio das leis.

A noção de "transplante legal" desenvolvida por Alan Watson e revisada por Cotterrell (2001) e outros autores procura exatamente dar conta das mudanças nos sistemas jurídicos ao tratar de perspectivas que consideram o processo de incorporação de expedientes legais, leis, instituições e até de um código inteiro de um país por outro, como um fenômeno social normal. Watson defende uma quase total independência e autonomia entre as esferas econômica, polí- 
tica e legal desenvolvendo a idéia de que o direito está insulado na sociedade. Neste sentido os processos de mudanças legais devem ser procurados nas formas específicas de positivação das normas e na comunicação específica entre as leis e em seus canais específicos de comunicação. A idéia, portanto, de transplante legal em Alan Watson está muito associada a dois pressupostos. O primeiro o de que a lei positivada constitui um universo particular com regras e princípios próprios e relativamente autônomos em relação às outras esferas da vida social; o segundo, o de que esta cultura própria das leis é objeto de escrutínio por um grupo de especialistas que se dedicam às tarefas de interpretação e operacionalização de seus usos e constituem por seu turno uma cultura própria de práticas, conhecimentos e valores próprios de especialistas. Daí que as mudanças e alterações dos sistemas legais sejam basicamente o resultado da ação e do conhecimento de especialistas nas leis positivadas.

Como um todo, a teoria de Watson postula, não sem alguma razão, que as teorias sociológicas sobre o Direito são fundamentalmente funcionalistas nos seus pressupostos sobre a determinação social das leis sobre os sistemas jurídicos. Uma interpretação mais generosa da obra de Watson, como a que propõe o próprio Ewald, afirma que o que aquele autor está postulando, na realidade, é que existem uma recíproca e complexa multideterminação entre o Direito e as relações sociais e não uma determinação unidimensional e unívoca. Se por um lado as proposições tradicionais da Sociologia do Direito procuram descrever e aclarar os contextos específicos (sociais, políticos e econômicos) nos quais as leis são criadas, estas teorias sociológicas são flagrantemente despreparadas para explicar alguns princípios legais irracionais e desconexos com a realidade social, especialmente aqueles resultantes de "sobrevivências" de dispositivos jurídicos e leis francamente disfuncionais às sociedades nas quais se situam.

Cotterrell (2001, p. 79) sustenta, por seu turno, que é necessário agregar a esta idéia de "transplante legal" as teorias que dêem conta da influência das diferentes culturas profissionais, estilos, formas e práticas de diferentes sistemas legais. O sucesso ou o fracasso no "transplante legal" dependerá em última análise, segundo este autor, da organização, formação educacional e flexibilidade da administração e das práticas do sistema judicial para adaptação de idéias exóticas às condições locais. Dependerá, também, da capacidade dos sistemas jurídicos maximizarem incentivos e removerem resistências à aceitação popular das novas idéias jurídicas. $\mathrm{O}$ Direito, complementa o autor, é parte da vida das comunidades e um aspecto das suas experiências sociais (COTTERRELL, 2001, p. 80). Numa perspectiva sociológica mais ampla, outros tipos de tradições comunitárias que não apenas aquelas dos juristas são importantes para situar a forma da influência das leis transplantadas no seio daquelas sociedades que as recepcionam. 
Nossa perspectiva transculturalista parte do mesmo pressuposto sociológico de que o Direito é um dado da cultura e não uma cultura à parte, mas não supõe qualquer tipo de funcionalidade entre as leis e um tipo específico de dominação. No caso brasileiro, para ficarmos num exemplo mais próximo e conhecido, o período do autoritarismo político liderado pelos militares manteve intactos todos os códigos legais, o direito civil, o criminal, o comercial, e até mesmo o trabalhista. Pôde, assim, impor um regime de restrições muito amplas aos direitos políticos dos cidadãos com alguns poucos decretos como os chamados Atos Institucionais, estes sim funcionais ao exercício do poder pelos militares. Vemos, assim, sentido nas críticas de Alan Watson ao funcionalismo dominante nas teses da Sociologia do Direito, e a suposição mecanicista nelas predominante que associa as mudanças nas relações sociais e reflexos diretos e imediatos na estrutura dos sistemas legais sem quaisquer mediações. Também, concordamos com a compreensão de Watson de que não são apenas as relações sociais que provocam mudanças no Direito, mas o contrário também é verdadeiro, i. e., que o Direito também provoca mudanças nas relações sociais. Essa relação de mão dupla pode ser ilustrada de forma muito clara com a legislação trabalhista brasileira criada pelo regime autoritário de Getúlio Vargas e voltada para a regulamentação das relações trabalhistas predominantemente urbanas e industriais num contexto de uma economia agro-exportadora. No entanto, consideramos extremada a tese geral de Watson sobre o insulamento do Direito frente as demais esferas da vida social. O Direito, como dissemos, é um dado da cultura, um complexo de signos e acervo de recursos cognitivos de interpretação, e não um mundo à parte.

Contudo, diferentemente de Watson, acreditamos que, embora pareça claro que há um código específico da comunicação jurídica e uma lógica intrínseca na redução das relações sociais ao código do lícito e do ilícito, nos parece extravagante a idéia de que possamos pensar relações jurídicas produzidas no vazio social e sem a influência de definições morais sobre o justo e sem as noções moralmente circunscritas sobre o certo e o errado. Enquanto dado de cultura o Direito deve ser entendido, segundo nossa perspectiva, como parte da produção de sentidos e significados mais amplos das relações que constroem entre si os membros da comunidade leiga e do senso comum. A elite jurídica retira dessas redes mais amplas de sentidos e representações culturais a matéria de suas abstrações. E, se muitas das vezes se comunicam em linguagem e cadeia de signos e significados particulares, como arte e artefato de especialistas, como defende Alan Watson, ou como linguagem especialíssima expressa em um código próprio, não deixa, por isso, de ser notável que esses expedientes reforçam um caráter político e de destaque social de constituição da corporação de juristas como um grupo com interesses próprios. 
Da mesma forma, as comunidades de leigos se apropriam das redes de instituições legais e das próprias leis interpretando-as e aplicando-as nas suas ações práticas. Por exemplo: leis de defesa do consumidor são invocadas a todo o momento nas relações de consumo e prestação de serviços, entre vendedores e compradores que as aplicam a seu modo na compra e venda de mercadorias e serviços. Acordos e litígios são fixados nas relações cotidianas com a apropriação rotineira que os indivíduos fazem daquilo que compreendem das leis, com efeitos e resultados práticos sobre as relações sociais. A própria linguagem aplicada às situações muito objetivas dos direitos fundamentais, como o de propriedade, reflete essa situação quando a figura legal do "usucapi", por exemplo, se transforma em "uso campeão" nas disputas entre leigos pela propriedade de bens imóveis.

Transplantes legais reforçam, portanto, a noção de uma intensa comunicação entre culturas legais divergentes e reforçam nossa crença na possibilidade de criação de uma legislação sobre direitos humanos que afirme uma universalidade de princípios sem desconhecer diferenças.

\section{CONCLUSÃO}

As noções de cultura legal e de transplantes legais permitem-nos vislumbrar a difusão de regras, de práticas e até mesmo de codificações legais de um país a outro, de uma cultura à outra, refletindo o dinamismo próprio das sociedades. A incorporação de expedientes legais de um sistema legal a outro pode se dar de maneira impositiva, como reflexo de mudanças oriundas da sucessão de grupos de poder caracterizando alterações que sirvam mais adequadamente aos interesses do status quo. Pode ocorrer também como resultado da percepção de grupos desprivilegiados dentro de uma sociedade que vislumbrem nos dispositivos de um Direito extraterritorial a oportunidade para defesa de seus modos e estilos próprios de vida.

Essa ampla transação de significados e sentidos sobre a lei e sobre o justo garante às diferentes sociedades a possibilidade de comunicação intercultural baseada no suporte interpretativo que constitui a natureza mesma das culturas.

Neste sentido acreditamos que as noções de Direitos Humanos podem ser plenamente reconhecíveis em qualquer padrão cultural humano, não importando quão diferentes dos nossos eles possam ser. Cultura é subjetivação, é interpretação e é comunicação. A cultura legal como subcultura das sociedades facilita a comunicação de sentidos expressos pelas noções variáveis do ilícito e do ilícito. Isto nos permite vislumbrar uma carta universal de Direitos Humanos, i.e., 
a construção de uma codificação de leis e preceitos legais que sejam universalizáveis em algum tempo senão como realidade imediata pelo menos como possibilidade real.

\section{REFERÊNCIAS}

BAUMAN, Zymunt. O mal-estar da pós-modernidade. Rio de Janeiro: Jorge Zahar, 1988.

BOAS, Franz. The mind of primitive man. New York: Macmillan, 1938.

CLASTRES, Pierre. A sociedade contra o Estado. Rio de Janeiro: Francisco Alves, 1988.

COTTERRELL, Roger. Adapting legal cultures. Oxford: Hart, 2001.

DOEKER-MACH, Guenther; ZIEGERT, Klaus. A. law and legal culture in comparative perspective. Stuttgart: Franz Steiner, 2004.

FRIEDMAN, Lawrence. The legal sistem: a social perspective. New York: Russel Sage Foundation, 1975.

GEERTZ, Cliford. A interpretação das culturas. Petrópolis: Vozes, 2001.

GIDDENS, Anthony. As conseqüências da modernidade. São Paulo: Editora da Unesp, 1991.

LARAIA, Roque de Barros. Cultura. Rio de Janeiro: Jorge Zahar, 2006.

LYOTARD, Jean-Francois. The post-modern condition. Minneapolis: University of Minneapolis Press, 1985.

NONET, Philippe; SELZNICK, Philip. Law and society in transition. London: Transaction Publishers, 2001.Z

PARSONS, Talcott. The social sistem. Glengoe: Free Press, 1951.

RECEBIDO: 03/11/2010

APROVADO: $29 / 11 / 2010$ 